\title{
Neonatal Hemoperitoneum: Diagnosis Always Delicate
}

\author{
Gneneyeri Joseph Ouattara ${ }^{1}$, Lassina Cisse ${ }^{1}$, Mohamed-Ali Latchtar ${ }^{2}$, Sabine Irtan ${ }^{3}$ \\ ${ }^{1}$ Department of Paediatrics, Division of Neonatology, University Teaching Hospital of Treichville, Abidjan, Côte d'Ivoire \\ ${ }^{2}$ Division of Neonatology, Armand Trousseau Hospital, Paris, France \\ ${ }^{3}$ Department of Visceral Surgery, Armand Trousseau Hospital, Paris, France \\ Email: ^jgouattara@yahoo.fr
}

How to cite this paper: Ouattara, G.J., Cisse, L., Latchtar, M. and Irtan, S. (2017) Neonatal Hemoperitoneum: Diagnosis Always Delicate. Open Journal of Pediatrics, 7, 192-196. https://doi.org/10.4236/ojped.2017.73022

Received: August 5, 2017

Accepted: September 17, 2017

Published: September 20, 2017

Copyright (C) 2017 by authors and Scientific Research Publishing Inc. This work is licensed under the Creative Commons Attribution International License (CC BY 4.0).

http://creativecommons.org/licenses/by/4.0/

\section{(c) (i) Open Access}

\begin{abstract}
The hemoperitoneum is a rare and severe disease in neonatal period that can cause a condition of hemorrhagic shock. We presented the case of an infant hospitalized for hemodynamic disorders which could to suspect maternofetal infection. The clinical deterioration with the appearance of shock signs, anemia, abdominal distension and Ultrasound allowed to correct diagnosis. Labour dystocia (apart from unnoticed minimal obstetrical trauma) does not seem to be responsible for hemoperitoneum as the majority of the reported cases. According to current recommendations, the treatment of this condition is primarily based on reanimation measures. Surgery is rarely needed in certain cases. Conservative treatment should be considered.
\end{abstract}

\section{Keywords}

Diagnosis, Hemoperitoneum, Neonatal

\section{Introduction}

The hemoperitoneum caused by spleen rupture is an uncommon and severe illness in a newborn infant [1] [2]. It is a life-threatening condition resulting from a shock condition, and therefore, requiring a rapid and precise diagnosis. Treatment strategies should be either conservative to prevent infectious complications or surgical, which is highly challenging in the hemorrhagic context. Traumatism is the leading cause of hemoperitoneum.

\section{Case Presentation}

The newborn A.S. was born on July 7, 2015 at the level II maternity (Saint Maurice hospital) at the end of 38-week amenorrhea. He weighed $3050 \mathrm{~g}$, was $45 \mathrm{~cm}$ 
with a head circumference of $35 \mathrm{~cm}$. His 27-year-old mother was at her third pregnancy and third parity. He had no family history of hematologic pathology.

The pregnancy was normal with regular follow-up. The mother had taken no medication, such as isoniazid, phenytoin, and phenobarbital, which were likely to cause coagulation disorders.

Spontaneous vaginal delivery with cephalic presentation was normally done. However, a double nuchal cord was found, and the delivery of baby was quickly done without any complication nor particular gesture. The newborn had a good adaptation to extra-uterine life with an APGAR score of 10 at five minutes.

At the third hour of life, the initial physical examination of the newborn showed peripheral circulatory disorders, including pallor, grayish skin, petechiae of the neck and the face, and algia. The external genital organs were normal.

In addition, the newborn refused to nurse and his mother's vaginal swab was positive to group B streptococcus. These signs contributed to suspect early neonatal infection. The biological examination showed a slight anaemia $(12.9 \mathrm{~g} / \mathrm{dl}$, Reference Value $(\mathrm{RV})>14 \mathrm{~g} / \mathrm{dl})$ and a Reference CRP $(<1 \mathrm{mg} / \mathrm{l}, \mathrm{RV}<4 \mathrm{mg} / \mathrm{l})$. The baby received vascular perfusion with physiological saline $(15 \mathrm{ml} / \mathrm{kg})$ and triple antibiotics, consisted of cefotaxime, amoxicillin, and gentamycin. The Kleihauer test was negative.

At the $10^{\text {th }}$ hour of life, a bruised swelling occurred in the right testicle, and thus, suggesting a testicular torsion. The testicular ultrasound displayed a lack of vasculature of the left testicle and a normal right testicle. As a result, the newborn was admitted at the Emergency Unit of the Armand Trousseau Hospital for adequate care at the $13^{\text {th }}$ hour of life. At the 14th hour of life, the clinical examination revealed a marked pallor, a painful abdomen, and a bruised right testicle within an uncomfortable newborn, and the anaemia was severe with $5 \mathrm{~g} / \mathrm{dl}$ of hemoglobin. Hemoperiteum was highly suspected in front of all these signs.

Abdominal ultrasound showed hemorrhagic ascites, splenic hematoma, and normal liver, and therefore, confirming hemoperitoneum. Testicular ultrasound identified hemorrhagic hydrocele without testicular lesion. Transfontanellar ultrasound was normal. The newborn was transferred to the Pediatric Surgery Department, where he benefited from reanimation measures, including hematologic and cardio-circulatory care. The patient was monitored twice daily for early days and then daily.

The patient received urgently a transfusion of red blood cell concentrates (30 $\mathrm{ml} / \mathrm{kg})$ and fresh frozen Plasma $(10 \mathrm{ml} / \mathrm{kg})$ after blood tests were performed to detect etiology and complication. This treatment allowed quickly to increase hemoglobin rate to $10.5 \mathrm{~g} / \mathrm{dl}$ and hematocrit to $31.6 \%$. The hemostasis tests showed $204,000 / \mathrm{mm}^{3}$ of platelets, 1.36 of Factor I, 20\% of Factor II, $60 \%$ of Factor $\mathrm{V}$, and 5.51 of dimers.

The newborn suffered from a syndrome of multivisceral failure during the hospitalization. He had rhabdomyolysis with CPK of 1633 UI on day 1 and of 317 UI on day 5 of hospitalization. He presented hepatic cytolysis with ASAT/ALAT of $185 \mathrm{UI} / 102 \mathrm{UI}$ on day 1 , of $275 \mathrm{UI} / 221 \mathrm{IU}$ on day 2, and of $40 \mathrm{IU} / 103 \mathrm{UI}$ on 
day 5, followed by a normalization of ASAT/ALAT (48 UI/55 UI) on day 9 of hospitalization. Gamma-GT and alkaline phosphatase were 99 UI and 102 UI on day 5 , respectively. On day 1 of hospitalization, uremia and creatininemia were 5 $\mathrm{mmol} / \mathrm{l}$ and $131 \mathrm{mmol} / \mathrm{l}$ in kidney failure with conserved diuresis, respectitvely. On day 2, uremia $(4.3 \mathrm{mmol} / \mathrm{l})$ and creatininemia $(102 \mathrm{mmol} / \mathrm{l})$ were rapidly corrected. Uremia $(1.3 \mathrm{mmol} / \mathrm{l}$ and creatininemia $(54 \mathrm{mmol} / \mathrm{l})$ were normal on day 5.

At respiratory level, newborn infant remained stable under ambient conditions. The saturation was more than $94 \%$. He did not suffer from hypercapnia. The metabolic acidosis (7.06), found upon admission, was corrected to 7.4. Metabolic disorders characterized by the increase of lactates $(19 \mathrm{mmol} / \mathrm{l})$ were urgently reduced to $1.7 \mathrm{mmol} / \mathrm{l}$. Phospho-calcium and other ions tests were normal. Total bilirubin was $167 \mathrm{mmol} / \mathrm{l}$ on day 4 , and the baby received a classic phototherapy of 3 hours out of 6 within 24 hours.

At infectious level, antibiotherapy was stopped after 48 hours of hospitalization because of negative value of 3 CRP tests and blood cultures. Nosocomial infection caused by multidrug-resistant bacteria was not found, and PCR detection of herpes simplex virus was negative at the admission.

The patient was able to nurse, and the perfusions were stopped on day 5 of hospitalization.

The therapy was pursued and led to a satisfactory condition of the newborn. On days 5 and 9 , he received a double transfusion of red blood cell concentrates which raised hemoglobin level from $13.1 \mathrm{~g} / \mathrm{dl}$ to $16,2 \mathrm{~g} / \mathrm{dl}$ with $45 \%$ of hematocrit without secondary deglobulisation.

On day 12, the newborn was released from the hospital with superficial hematoma of the left inguinal region and slight and indolent induration of the left scrotum.

The follow-up of the patient was characterized by a gradual regression of the splenic hematoma from different ultrasounds: $2 \mathrm{~cm}$ on July 8, 2015 (picture 1); $1.6 \mathrm{~cm}$ on July 29 (picture 2), 2015; $1.1 \mathrm{~cm}$ on August 1, 2015 (picture 3); total disappearance on January 25, 2016.

\section{Discussion}

The intra-abdominal hematoma related to spontaneous organ lesions of organs is uncommon in the newborn. Few cases of hemoperiteum have been reported in the literature and most of them have been caused by traumatism during dystocia of labor since its first description in 1948 [3].

Risk factors favoring traumatism in newborn infant were high birth weight, splenomegaly, and coagulopathy due maternal anticonvulsant intake, such as phenytoin and phenobarbital [4] [5]. The usual underlying mechanism of hemoperitoneum is related to the spleen rupture from obstetrical traumatism [5]. In addition, splenic rupture could be due to intrinsic disease, including mucopolysaccharidosis. The mucopolysaccharidosis is a metabolic illness which may 
be revealed by splenomegaly during prenatal or neonatal period. In contrast, literature data did not report any case of hemoperitoneum occurring in mucopolysaccharidosis in newborn [6].

The hemoperitoneum should be differentiated from testicular torsion in the newborn male and other surgical pathologies in case of bruised swelling of the scrotum and the labia majora. The spontaneous evolution of hemoperitoneum rapidly leads to signs of shock, sensitive abdominal distension, scrotal swelling in the newborn boy, the labia majora swelling in the newborn girl, and pallor.

These signs require immediate care combining a vascular perfusion and a blood transfusion. The diagnosis can be rapidly made by non invasive and accessible methods (ultrasound) compared with old invasive methods (surgery) and autopsy [3].

In our case, the hemoperitoneum was diagnosed relatively late at the $13^{\text {th }}$ hour of life. The late diagnosis would result from out-born birth, mistaken initial diagnosis of early neonatal infection, followed by testicular torsion, and no discovery of risk factors (normal birth weight, no medical history of traumatism at childbirth and coagulopathy). Our patient was admitted to Intensive Care Unit for globular concentrate and a vascular perfusion under monitoring of hemodynamic variables. Hemostasis tests were normal.

Our patient did not undergo surgery for the splenic hematoma and the hemoperitoneum; however, he benefited from efficient clinical, biological, and ultrasonographic monitoring of the patient. The care of our case is different from that of Mekkil et al. in Tunisia, where most of newborns were surgically treated [7].

In the literature, the most common differential diagnoses are vaginal hydrocele, testicular torsion, complicated inguinoscrotal hernia in case scrotal swelling of the newborn male the [8] [9].

In addition, the presence of a scrotal swelling with hematoma should indicate an intra-abdominal surgical pathology. The primary signs of hemoperitoneum are respiratory symptoms (respiratory distress) and hemodynamic disorders (anemia and shock conditions) which may lead to respiratory and hematologic diseases, respectively.

In this context, the examination the newborn should be thorough, systematic and complete to identify potential causes. Because of these cases reported in the literature, our clinical case is rare in which newborn suffered from spleen lesions at birth and were clinically stable.

Ultrasound and magnetic resonance imaging are relevant for the diagnosis and the extension assessment of other organ lesions and have considerably improved the treatment of this surgical pathology. The surgery is required for aggravation, hemodynamic instability or rebleeding despite an effective reanimation [10] [11] [12].

Thus, the clinical management of this disease is multidisciplinary involving, neonatologists, paediatric surgeons, radiologists, and emergency physicians. 


\section{Conclusions}

The neonatal hemoperitoneum is rare and life-threatening emergency. The prevention of this disease depends on the adequate obstetrical care which should include caesarean section and systematic prescription of vitamin $\mathrm{K}$ to newborns. The diagnosis of hemoperitoneum might simulate a surgical pathology that requires an urgent surgery. However, thorough and regular clinical examination, rapid clinical evolution causing hemodynamic disorders, and ultrasound are relevant to confirm the diagnosis of this condition. The treatment is essentially based on hemato-cardio-circulatory reanimation.

NB: Informed consent was obtained from the patient's family to report this case.

\section{References}

[1] Balliu, P.R., Bregante, J., Perez-Valasco, M.C., et al. (2004) Splenic Haemorrhage in a New Born as the First Manifestation of Wadering Spleen Syndrome. Journal of Pediatric Surgery, 39, 240-242. https://doi.org/10.1016/j.jpedsurg.2003.10.025

[2] Hui, C.M. and Tsui, K.Y. (2002) Splenic Rupture in a Newborn. Journal of Pediatric Surgery, 37, E3. https://doi.org/10.1053/jpsu.2002.31641

[3] Gruenwald, P. (1948) Rupture of the Liver and Spleen in the Newborn Infant. Journal of Pediatrics, 33, 195. https://doi.org/10.1016/S0022-3476(48)80057-0

[4] Traggis, D.G., Maunz, D.L. and Baroudy, R. (1984) Splenic Hemmorhage in a Neonate of a Mother on Anticonvulsivant Therapy. Journal of Pediatric Surgery, 19, 598-599. https://doi.org/10.1016/S0022-3468(84)80114-1

[5] Bickler, S., Ramachandran, V., Gittes, G.K., et al. (2000) Nonoperative Management of Newborn Splenic Injury: A Case Report. Journal of Pediatric Surgery, 35, 500-501. https://doi.org/10.1016/S0022-3468(00)90222-7

[6] Brock, D.J., Gordon, H., Seligman, S., et al. (1971) Antenatal Detection of Hurler Syndrome. Lancet, 2, 1324-1325. https://doi.org/10.1016/S0140-6736(71)90654-4

[7] Mekkil, M., Nouril, A., Belghith, M., Krichenel, I., et al. (2000) Hémopéritoine Néonatal. [Neonatal Hemoperitoneum] Pediatrics Archives, 7, 385-387. https://doi.org/10.1016/S0929-693X(00)88833-8

[8] Perdomo, Y., Fiore, N. and Reyna, T. (2003) Splenic Injury with Isolated Scrotal Findings in a Stable Newborn. Journal of Pediatric Surgery, 38, 1673-1675.

https://doi.org/10.1016/S0022-3468(03)00581-5

[9] Yang, W.T., KU, K.W. and Metreweli, C. (1995) Case Report: Neonatal Adrenal Haemorrhage Presenting as an Acute Right Scrotal Swelling (Haematoma)-Value of Ultrasound. Clinical Radiology, 50, 127-129. https://doi.org/10.1016/S0009-9260(05)82998-8

[10] Deberdt, P., Courootin, C. and Paoouin, M. (1988) Acute Anemia by Hemoperitoneum Revealing a Hemorrhagic Disease of the Newborn. Pediatrics Archives, 45, 47-48.

[11] Cohen, J.Y., Care, L., Sobin, B., Boze, J.C. and Mouzard, A. (1982) Subcapsular Hematomas of the Liver in Newborns. Radiology Annals, 25, 34-40.

[12] Cywes, S., Rode, H. and Millard, A. (1985) Blunt Liver Trauma in Children: Non Operative Management. Journal of Pediatric Surgery, 20, 14-18. https://doi.org/10.1016/S0022-3468(85)80383-3 
Submit or recommend next manuscript to SCIRP and we will provide best service for you:

Accepting pre-submission inquiries through Email, Facebook, LinkedIn, Twitter, etc. A wide selection of journals (inclusive of 9 subjects, more than 200 journals)

Providing 24-hour high-quality service

User-friendly online submission system

Fair and swift peer-review system

Efficient typesetting and proofreading procedure

Display of the result of downloads and visits, as well as the number of cited articles Maximum dissemination of your research work

Submit your manuscript at: http://papersubmission.scirp.org/

Or contact ojped@scirp.org 